\title{
Fundamentos culturales para un modelo educativo emergente en la educación superior tecnológica
}

\author{
Manuel Villarruel-Fuentes* \\ iD https://orcid.org/0000-0002-1174-0528
}

Recibido: 28 de febrero, 2019 - Aceptado: 18 de julio, 2019

\section{RESUMEN}

La tendencia a privilegiar el progreso social a partir de la educación ha condicionado el diseño de modelos educativos centrados en la ciencia y la tecnología. Desde esta perspectiva se favorece la adquisición de habilidades para el trabajo, soslayándose la importancia de la cultura como generadora de programas formativos. Con base en ello se presenta una propuesta alternativa para el diseño de modelos educativos pensados desde la cultura, cuyo propósito es la formación integral y el desarrollo del talento humano.

Palabras clave: Desarrollo humano, cultura, humanismo.

Formato de citación según APA

Villarruel Fuentes, M. (2019). Fundamentos culturales para un modelo educativo emergente en la educación superior tecnológica. Revista Espiga, 18 (38), 141-157.

\section{Formato de citación según Chicago-Deusto}

Villarruel Fuentes, Manuel (2019). «Fundamentos culturales para un modelo educativo emergente en la educación superior tecnológica». Revista Espiga 18, n. ${ }^{\circ} 38$ (juliodiciembre, 2019): 141-157.

* Profesor-Investigador de tiempo completo en el Tecnológico Nacional de México/Instituto Tecnológico de Úrsulo Galván, Veracruz, México. Ingeniero Agrónomo especialista en Zootecnia, maestro en Educación y Doctor en Educación. Diplomado en Sistemas Educativos Abiertos y a Distancia, diplomado en Competencias Docentes, diplomado en Tutorías. Perfil PRODEP. Miembro del Consejo Mexicano de Investigación Educativa, miembro del Sistema Nacional de Investigadores en México. Líder del Cuerpo Académico «Cultura Académica y Desarrollo Social Sustentable», líder de la Red Veracruzana de Investigación e Innovación Educativa y de la línea «Docencia y Aprendizaje», México. Correo: dr.villarruel.fuentes@gmail.com 


\section{Introducción}

En medio de fuertes debates en torno a lo que debe ser la educación en América Latina, es posible identificar una problemática vinculada con la carencia de modelos curriculares que orienten el derrotero por seguir dentro de la educación superior. Sobre esta base se discute la pertinencia de incorporar las premisas de una educación netamente tecnológica, o bien, dar cabida a enfoques más humanistas dentro de la formación escolar ${ }^{1}$. Incluso hay quienes apuestan por la combinación de ambas, en una especie de coexistencia paradigmática que no acaba de encontrar los fundamentos epistémicos que permitan sustentar el diseño de modelos educativos.

Se destaca cómo las actuales tendencias educativas se muestran proclives al modelo de sociedad tecnológica, cuyo concepto «nace como consecuencias de todas las actividades en las que se ha hecho la sociedad global, a partir de la entrada de las sociedades posindustriales en la que se han dado grandes cambios» ${ }^{2}$. Lo que Minguet-Melián y $\operatorname{Read}^{3}$ atribuyen al mayor aprovechamiento de la información y el conocimiento, propiciado por las Tecnologías de la Información y la Comunicación, condición denominada era del conocimiento, desde la que se afirma una relación directa entre poseer información y generar conocimiento, sin considerar la necesidad de modelos educativos que posibiliten esta compleja transición.

Bajo entornos cargados de confusión metodológica, derivados del relajamiento de los postulados teóricos que deben soportar toda propuesta educativa innovadora, la constante ha sido la presentación de proyectos fundamentados en distintas doctrinas filosóficas, múltiples ideas y puntos de vista, que tienden más a la valoración de condiciones ideales, que a la formulación de un sistema teórico-conceptual que modele fuentes, rasgos y estilos de educar.

Es necesario enfatizar que un modelo educativo no debe ser una carta descriptiva donde se recreen misiones y visiones del deber ser, sino guías orientadoras de la relación existente entre estudiantes y maestros, a la vez que esclarecedoras del significado de educar, sus fines y medios; dicho de otra forma: directrices para identificar los enfoques pedagógicos y andragógicos que serán adoptados a partir de la propuesta. Se trata de definir un perfil de identidad anidado en las funciones sustantivas de los planteles de educación superior y enmarcado en valores que se signifiquen por sus principios éticos, cuya calidad, como ejes rectores, otorgue certidumbre a la planeación estratégica institucional.

1. José Ricardo Díaz-Caballero, "Humanismo y tecnología», Revista Cubana de Ingeniería, 1, n. ${ }^{\circ}$ 2, (2010): 71-74, acceso: 2 de agosto, 2019, http://rci.cujae.edu.cu/index.php/rci/article/view/22/23. Alejandro Ocampo-Almazán, «Humanismo y tecnología: algunas ideas para salir de la exclusión», Razón y Palabra, Primera Revista Electrónica en Iberoamérica Especializada en Comunicación, n. ${ }^{\circ} 89$ (2015): 1-9, acceso: 2 de agosto, 2019, http://www.razonypalabra.org.mx/N/N89/V89/25_Ocampo_V89.pdf

2. Juan Carlos Piedra-Calderón, Rubén González-Crespo y José Javier Rainer, «Sociedades tecnológicas», Sociedad y Utopía, Revista de Ciencias Sociales, n. ${ }^{\circ} 4$ (2014), 18-33, acceso: 2 de agosto, 2019, http://www. sociedadyutopia.es/images/revistas/44/E01.pdf

3. Jesús María Minguet-Melián y Tim Read, Informática Fundamental (Madrid: Editorial Universitaria Ramón Areces, 2008). 
En el mejor de los casos, un modelo educativo debe recuperar el basamento elemental que interprete y defina lo que la sociedad es, para de ahí proponer un nuevo escenario de actuación, donde la cultura sea reinterpretada para transformarla, y no para perpetuar la hegemonía de ciertos grupos o intereses.

No se trata únicamente de definir los marcos interpretativos de orden filosófico, económico y administrativo, identificados hasta ahora como estrategias monolíticas de un pensamiento dominante que se asume garante del desarrollo y el progreso social; por el contrario, debe anticipar los profundos cambios a los que la humanidad estará sujeta, lo que trasciende la formación escolar destinada al empleo en la industria y para ella ${ }^{4}$. Sobre este particular, la educación superior

«debe desarrollar planteamientos interdisciplinarios y transdisciplinarios que refuercen actividades encaminadas a erradicar la pobreza, las enfermedades, la intolerancia, la violencia, el analfabetismo, el hambre y el deterioro del medio ambiente, entre otros problemas que la sociedad contemporánea busca resolver» ${ }^{5}$.

Una aspiración de esta naturaleza exige trascender las posturas centralistas que conciben a la educación como la adquisición de habilidades para el trabajo, sustentadas en el desarrollo de competencias laborales. Si bien este ideario funcionalista y pragmático se presenta con el distintivo de la integralidad y como prescripción para el aprendizaje permanente, a partir de la consigna axiomática de aprender a aprender como competencia para lograr la compresión, desde donde «se busca el desarrollo integral de la persona a través de la imaginación, la creatividad y el pensamiento crítico, que permita el conocimiento de uno mismo y del otro, superando las fronteras del individualismo, donde la gran beneficiada sea la sociedad $»^{6}$, lo cierto es que en la práctica no ha demostrado dicha condición formativa, al ser el sector industrial/empresarial el gran beneficiado.

A partir de esta perspectiva, los modelos educativos tienen que sentar las bases para el diseño y rediseño de planes y programas de estudio, su evaluación y realimentación en el tiempo; pero a la vez, deben precisar bajo qué entornos serán concebidos, así como los estándares culturales a los que se vincularán ${ }^{7}$. No es válido argumentar a favor de una propuesta, asumiéndola en el discurso como necesaria, mientras en la realidad se muestra

4. Campos en los que impera la Economía del Conocimiento. A decir de Hualde (2005): «El predominio de la racionalidad económica en los procesos sociales ha influido seriamente sobre las visiones acerca del sentido de la educación, del papel de las instituciones, de sus estructuras organizativas y de la propia relevancia del sistema educativo como institución creadora y reproductora del conocimiento» (p.108).

5. Luis Felipe Guerrero-Agripino, "Modelo Educativo de la Universidad de Guanajuato», Guanajuato: Universidad de Guanajuato, 2011, acceso: 6 de agosto de 2019, http://www.ugto.mx/images/pdf/modeloeducativo-y-sus-modelos-academicos-universidad-de-guanajuato.pdf

6. Laura Massimino-Amoresano, «Tecnología y educación: El humanista tecnólogo. Deconstruyendo la frontera entre las dos culturas», ILCEA, $n .{ }^{\circ} 18$ (2013), acceso: 2 de agosto, 2019, https://journals.openedition. org/ilcea/2096

7. Se entiende como modelo educativo emergente toda propuesta teórico-conceptual encaminada a ofrecer una alternativa de cambio a los enfoques tradicionales de enseñanza-aprendizaje institucionalizados; contempla para ello una amplia gama de referentes (sociales, administrativos, filosóficos, culturales, entre otros), cuyo objetivo es trascender lo ya establecido, a partir del diseño o rediseño de un nuevo objetivo rector, misión y visión educativa. 
alejada de las aspiraciones de una sociedad que exige cambios constantes en su estructura operativa; demandas que suponen la aparición de nuevos actores sociales, que en calidad de gestores culturales hagan frente tanto a la diversidad ideológica como a la multiculturalidad, condiciones cada vez más frecuentes en el nivel superior.

Más allá del ideal de una educación superior innovadora y creativa, para muchos integral, que fortalezca la dinámica social, sobre todo en aquellos aspectos valorados como indispensables para alcanzar los anhelos de equidad, paz y democracia, a la educación superior le corresponde ser más que la diseñadora de discursos y la salvaguarda de interés creados al margen de la sociedad y su cultura. Decir qué hacer no basta para saber cómo hacerlo y, lo que es más importante: por qué hacerlo. Este déficit se aprecia en muchas propuestas actualmente vigentes, como ejemplo se tiene lo referido por $\mathrm{Mu}-$ rueta et al. ${ }^{8}$, quien señala la necesidad de «desarrollar relaciones afectivas satisfactorias, estables y duraderas (familia, pareja, amistad, compañeros)» como prioridad en todos los niveles educativos.

Dicha prioridad deja entrever el sentido utópico de esta visión, trivializada al grado de suponer que un modelo educativo, organizado en planes y programas de estudio, puede concretar relaciones afectivas placenteras y duraderas. En todo caso, compete a otros subsistemas, dentro del macrosistema que representa el entorno sociocultural, corresponsabilizarse de estas acciones formativas. Las escuelas, vistas como «centros de transformación social $»^{9}$ deben competir con el efecto condicionante del medio ambiente, asumiéndose como verdaderos «campos de posibilidades educativas» ${ }^{10}$. Únicamente así, la sociedad podrá encontrar en las instituciones de nivel superior las nuevas propuestas de cambio cultural, desde las que se oriente el sentido y la naturaleza de las interrelaciones.

Bajo estas premisas se afirma que «el docente debe conocer el modelo educativo, entre más conocimiento tenga de este, le permitirá crear una planeación didáctica y uso de herramientas y técnicas acorde (sic) a cumplir objetivos que tendrán un impacto favorable en la educación de los estudiantes» $\rangle^{11}$, pero ello presenta una serie de dificultades, entre las que se destacan: la falta de formación pedagógica/andragógica de los maestros en el nivel superior, ausencia de diagnósticos referenciales que esclarezcan las condiciones y el entorno donde se desarrolla el hecho educativo, aunado a la ausencia de métricas precisas para evaluar la intervención didáctica del maestro.

En consideración de lo anterior, dos alternativas son posibles:

1) alinear el modelo educativo a las evaluaciones diagnósticas realizadas en las instituciones, con atención de las fortalezas, oportunidades, amenazas y debilidades expresadas en la infraestructura, equipo, colectivos académicos, personal de apoyo, programas sustantivos, entre otros;

8. Marco Eduardo Murueta, et al., Hacia un nuevo modelo educativo integral. Nuevos Modelos educativos (México: Manual Moderno, 2015), 24, acceso: 2 de agosto, 2019, https://www.transformacion-educativa. com/attachments/article/153/Libro\%2008\%20-\%20Nuevos\%20modelos\%20educativos.pdf

9. Ibíd., 25 .

10. Ibíd., 25 .

11. Ginne Ussi Guadalupe Apodaca-Orozco et al., «Modelos educativos: un reto para la educación en salud», Ra Ximhai, 13, n. ${ }^{\circ} 2$ (2017): 80, acceso: 2 de agosto, 2019 https://www.redalyc.org/pdf/461/46154510006.pdf 
2) centrar el modelo en las aspiraciones de logro, plasmadas en la misión y visión institucional, donde se interpretan los campos problemáticos vigentes y las megatendencias de solución, locales y globales, condición frecuente en las instituciones educativas de América Latina. Como ejemplo se tiene los modelos infundidos por la iniciativa Tuning América Latina ${ }^{12}$.

Con el objetivo de vislumbrar nuevas vías de reflexión e intervención para el diseño de modelos educativos orientados desde la cultura, que transciendan la visión tecnocientífica distintiva de la educación superior tecnológica, a continuación se presenta un análisis de sus posibilidades educativas y curriculares.

\section{Desarrollo}

\section{El modelo educativo como alternativa cultural}

Con la entrada del siglo XXI, la conceptualización de la cultura ha tomado rumbos inusitados. Hoy existen distintas acepciones para definir su sentido y orientación, sus fundamentos y el espectro de sus alcances. Mientras que antaño se entendía de manera restringida al referírsele en la Grecia Antigua a la crianza de un niño, y en su calidad de método como el camino para la instrucción y la educación perfecta (Paideya), ya en la Roma de Cicerón se empleaba el vocablo humanitas, refiriéndose a la educación perfecta o refinada, la cual era posible mediante el acceso a las «bellas artes» (filosofía, poesía, oratoria, entre otras), solo posibles entre los seres humanos sublimados, quienes se elevan sobre sí mismos hasta alcanzar su genuina y perfecta naturaleza; estos quehaceres más tarde fueron concebidos como artes liberales ${ }^{13}$, derogadas durante la Edad Media bajo el influjo de la cosmovisión religiosa y en muchos sentidos enciclopédica, encaminada a la alta especialización, accesible solo a unos cuantos (clérigos).

Bajo este contexto, la filosofía, entendida como la madre de todas las ciencias, dejó de tener sentido como camino al saber y a la sabiduría, en virtud de poseer el pensamiento religioso los cánones que explicarían todo «saber verdadero». No será hasta la Edad Moderna cuando se abrirá el camino para el pensamiento científico, entendido ahora desde el referente humano y no religioso -antropocentrismo-, asumiéndose lo natural como medio para muchos fines.

Sobre esta base, la cultura adquiere una condición asociada a las formas y los medios de producción, los que eventualmente habrán de desembocar en la denominada Revolución Industrial, caracterizada por la necesidad de alfabetizar a las personas encargadas de operar el naciente sistema industrial/empresarial. La alta especialización requerida para operar las cadenas productivas traerá un cambio sustancial en las formas de organización cultural, promotoras de una renovada jerarquización social. La llegada de la

12. Universidad de Deusto, «Reflexiones y perspectivas de la educación superior en América Latina» (informe final Proyecto Tuning 2004-2007, Bilbao, España: RGM, S.A., 2007), acceso: 2 de agosto, 2019, http:// tuningacademy.org/wp-content/uploads/2014/02/TuningLAIII_Final-Report_SP.pdf

13. Angelo Altieri-Megale, «¿Qué es la cultura?» La lámpara de Diógenes, 2, n. ${ }^{\circ}$ (2001): 15, acceso: 2 de agosto, 2019, https://www.redalyc.org/pdf/844/84420403.pdf 
Revolución Científico-Tecnológica (siglo XX) será determinante para entender la apetencia ideológica-conceptual por el desarrollo y el bienestar social. Al respeto, Maraña ${ }^{14}$ señala cómo «en las últimas décadas se ha profundizado sobre el concepto de desarrollo, incluyendo en él no sólo indicadores como el crecimiento económico o la producción, sino también incorporando factores considerados en la actualidad indispensables para el pleno desarrollo, un desarrollo no lineal».

Este discernimiento ayuda a entender lo que significa la cultura, aunque no está exento de confusión y debate. El propio Maraña ${ }^{15}$ enfatiza en que «la cultura, vista siempre como una cuestión compleja y de gran sensibilidad social y política, se ha convertido en nuestros tiempos en una palabra cliché, empleada de modo profuso en casi todos los contextos de nuestra realidad (políticos, sociales, educativos, económicos, etc.)». Ello ha vuelto complejo su papel como identificadora y definidora del desarrollo, al grado de volverla un concepto polisémico.

En conceptos de Geli de Ciurana, citado por Carbó-Ribugent ${ }^{16}$, la palabra cultura es una palabra maleta, que al igual que otras, como educación, pueden significar todo y no definir algo en concreto, sin saber exactamente a qué se refieren cuando se emplea. Mención aparte merece el sentido que se le otorga a la palabra cultura dentro del ámbito político y social, cargado de intensas controversias. Se destaca lo acontecido en la educación, donde «existen numerosas lecturas y diversas apropiaciones de la noción de cultura, y el problema es qué se incluye y qué se excluye de la misma» ${ }^{17}$.

En este tenor, es posible entender los rumbos que la política educativa ha seguido en América Latina, decantada hacia los aspectos culturales que la definen como un cúmulo de habilidades y destrezas propias de un campo laboral. La idea de asociar la cultura al trabajo deja entrever una intención que no siempre abona al desarrollo humano, sobre todo si se piensa que sus fines y medios se concretan lejanos a las aspiraciones de los grupos sociales, quienes terminan por aceptar a cambio de ser aceptados. Sobre esta vertiente, muchos modelos educativos han incorporado el factor cultural, sesgándolo hacia la dinámica social que prevalece en ciertas subculturas, tal como ocurre con el sector industrial. En aras de este propósito sublimado, se presta mayor atención al diseño curricular, su despliegue y operatividad, reafirmándose en él los propósitos de ciertos grupos dominantes y potenciando un carácter generalista dentro de la cultura, en la cual todos deben saber y hacer lo mismo. Su complejidad se aprecia al observar cómo:

... a pesar de que hablemos de políticas culturales, política y cultura muchas veces son visualizados como espacios que se repelen e incluso que deberían hacerlo. Frente a la creatividad y la libertad frecuentemente atribuidas a la cultura aparece el temor al autoritarismo del Estado o

14. Maider Maraña, «Cultura y desarrollo. Evolución y perspectivas» (Cuadernos de trabajo, UNESCO/Etxea, 3, 2010), acceso: 2 de agosto, 2019, http://www.unescoetxea.org/dokumentuak/Cultura_desarrollo.pdf

15. Ibíd., 4.

16. Gemma Carbó-Ribugent, La cultura, estrategia de cooperación al desarrollo (Girona: Documenta Universitaria, 2008).

17. Rubens Bayardo, «Sobre el financiamiento público de la cultura. Políticas culturales y economía cultural», NAyA (2002): 3, acceso: 2 de agosto, 2019, http://www.equiponaya.com.ar/congreso2002/ponencias/ rubens_bayardo.htm 
sus agencias, a la conversión de la cultura en mera propaganda, a su uso como herramienta de manipulación y de clientelismo. Es claro que todos estos abordajes y contraposiciones resultan absolutamente discutibles... ${ }^{18}$

Estas condiciones invocan una concepción de la cultura vista desde los ángulos de la economía y la administración de los recursos. Esto trae consigo una representación social de la cultura que el imaginario colectivo interpreta como elemental y necesaria. La meta central es posicionar, dentro de los modelos de desarrollo social, la idea de que la economía es su detonadora, al ser tangible y racional, mientras que la cultura, por inclinarse a lo espiritual, lúdico, intangible y emocional, tiende más al ejercicio ocioso del quehacer humano. Por ello, el Estado opta por tomar las riendas de su rumbo y concreción; para alcanzarlo, ningún medio es tan eficiente como la educación institucionalizada, nada mejor que el desarrollo de modelos que lo hagan posible.

\section{Modelos culturales como opción educativa}

La idea de hacer de la cultura una política de Estado y no de la economía una política cultural supone realizar cambios profundos en la idiosincrasia de las sociedades; sobre todo, de las formas de concebir la cultura a la luz de sus dinámicas. Se trata de pensar en lo que es común a los distintos grupos humanos para, desde ahí, gestionar los medios y alinear los fines en busca de lograr congruencia entre políticas y aspiraciones de logro, así como coherencia entre el discurso y lo que se puede alcanzar. La idea de transformar subyace a estos principios, tarea que puede ser conducida desde los espacios escolares de la educación formal. En conceptos de Tünnermann ${ }^{19}$, los procesos de transformación:

... generalmente se inician con la adopción de la gestión estratégica como el instrumento para mejorar el desempeño administrativo general, [...] la cuidadosa elaboración de diagnósticos institucionales y académicos, acompañadas de ejercicios de autoevaluación institucional, que permiten identificar las fortalezas, debilidades, amenazas y oportunidades [...], definir su visión y su misión institucional, su modelo educativo y académico y diseñar las políticas y estrategias que le permitirán el mejoramiento constante de su calidad y pertinencia.

Si bien estos postulados se ubican en sitios comunes del discurso oficial, lo novedoso estará en las formas en que estas estrategias y acciones son conducidas, así como el grado de intervención de los diversos actores sociales involucrados en su diseño e interpretación. No debe descartarse el papel que juegan los códigos lingüísticos y las matrices semánticas a las que se asocian, las cuales es necesario renovar, con el fin de dar paso a nuevas interpretaciones, incluso a nuevos engranajes conceptuales.

Bajo modificadas lógicas discursivas, el camino a la transformación puede significarse por su sentido de pertenencia a las cosmovisiones de los colectivos, quienes podrán asumir nuevos enfoques, desde la gestión y negociación de saberes, pensares, vivires

18. Rubens Bayardo, «La economía cultural, las políticas culturales y el financiamiento público de la cultura», Turismo y Patrimonio, n. 4 (2018): 59, acceso: 2 de agosto, 2019, http://ojs.revistaturismoypatrimonio. com/index.php/typ/article/view/143

19. Carlos Tünnermann Bernheim, Modelos educativos y académicos (Nicaragua: HISPAMER, 2008) 7-8. 
y decires. Diálogo que ha decir de Merçon, Camou-Guerrero, Núñez-Madrazo, Escalona-Aguilar ${ }^{20}$, «alude al paso que va de la asimilación, sustitución o destrucción de saberes (epistemicidio) a los procesos de escucha e inclusión, negociación multilateral, generación de acuerdos y construcción de nuevos saberes». Ello no significa abandonar el pensamiento científico decimonónico que tradicionalmente acompaña a las propuestas modélicas -asumido garante del saber verdadero-, sino de incorporar otras formas igualmente válidas de concebir la realidad, sobre todo la social. Como afirman Morin y Delgado ${ }^{21}$, «la ciencia y la tecnología no pueden ser excluidas, pero no tienen por qué pronunciar la última palabra».

Frente a este reto, la diversidad cultural se constituye en el factor clave para entender la complejidad inherente a los procesos de formación humana que tienen lugar en los centros escolares. La departamentalización con la cual se pretende resolver este conflicto, propia del pensamiento cartesiano, dispersa la cultura hacia dimensiones que se asumen independientes del todo, como es el caso de la ciencia y la tecnología; pero también de la economía, la política, la administración y, más recientemente, la ecología. La separación de estos entornos hace que la contienda por ganar espacio en las ideologías y dominar el pensamiento social, se vuelva el centro de sus debates, aunque también de sus propuestas. Entonces, no interesan tanto los fines, sino que ahora los medios cobran relevancia. Aquí es donde la economía, fuertemente empoderada por el saber científico, ocupa todos los espacios de entendimiento posibles. Desde sus preceptos todo es operable, fuera de ella no hay validez; el desarrollo social, explicado desde lo económico, se vuelve único y omnipresente. De esta forma la economía explica a la cultura y no la cultura a la economía.

Desde estas configuraciones, es posible aseverar la existencia de dos enfoques para abordar la cultura. La primera de ellas de carácter particular, donde se habla de una economía de la cultura, coligada a las denominadas industrias culturales -entre ellas la economía creativa-, integradoras de las acciones culturales encaminadas al desarrollo bajo los auspicios de la tradición (folclorización, asociado al patrimonio). Esta perspectiva ha sido relegada de los modelos educativos y las propuestas curriculares en el nivel superior. La segunda con propensiones universales, entendiéndose su abordaje como una tendencia moderna de identificar verdades homogéneas, a pesar de la heterogeneidad de los pueblos ${ }^{22}$. Este es el cauce que predomina en la educación superior tecnológica en Latinoamérica, respaldada por el denominado enfoque educativo basado en competencias profesionales, donde la experticia adquirida es indicadora de las habilidades que posee la persona, su dominio conceptual, procedimental y axiológico, bajo el supuesto de que existe una cultura única que debe ser reproducida (aldea global). Para lograr esta educación instructiva, se recurre a fetiches ideológicos y operativos: ninguno más eficaz que las Tecnologías de la Información y la Comunicación.

20. Juliana Merçon et. al., «¿Diálogo de saberes? La investigación acción participativa va más allá de lo que sabemos», Desicio, n. ${ }^{\circ} 38$ (2014): 30, https://cdn.crefal.org/CREFAL/revistas-decisio/decisio38_saber6.pdf

21. Edgar Morin y Carlos Jesús Delgado-Díaz, Reinventar la educación. Abrir caminos a la metamorfosis de la humanidad (México: UH, 2017) 28.

22. Luis Herrera, «La educación y la cultura: una lectura y propuesta desde la filosofía de la praxis», Sophia, Colección de Filosofía de la Educación, n. ${ }^{\circ} 1$ (enero-junio, 2006):186-231, acceso: 2 de agosto, 2019, http:// www.redalyc.org/pdf/4418/441846111004.pdf 
En coincidencia parcial con lo establecido por Villa ${ }^{23}$, quien sostiene que todas las escuelas «han sido y son definidas cotidianamente como instituciones donde se 'imparte cultura' o 'se enseña la cultura'. En forma genérica, la educación se define como transmisión de la cultura o enculturación»; sobre esta base, el principio esgrimido en el presente artículo se centra en la exigencia de atender el diseño de modelos educativos desde la gestión cultural, clarificando los simbolismos, representaciones y códigos que le son propios a las sociedades, con el propósito de generar cambios que favorezcan el bien vivir social, lo que exige preguntarse: ¿Qué es la cultura? Lo cual acentúa la importancia de definirla antes de debatir en torno a sus tipologías, como ocurre cuando se habla de diversidad cultural, libertad cultural, multiculturalidad e interculturalidad.

\section{Educar desde la cultura}

Más allá de las formas y estilos, de las políticas y los cambios, la intención de educar se ha mantenido inmutable a través del tiempo. Promover el cambio social desde las instituciones escolares ha sido una larga tradición que hunde sus raíces en la cultura griega y se proyecta al futuro desde el Renacimiento y la Ilustración, hasta alcanzar su pináculo en el modernismo y la posmodernidad. Tünnermann ${ }^{24}$ aclara que: «La tradición académica del siglo XIX y buena parte del XX está signada por la disciplinarización y profesionalización del conocimiento. $\mathrm{Y}$ si bien no es posible la interdisciplinariedad sin el dominio de las disciplinas, cada vez más el trabajo interdisciplinario se impone en el quehacer académico».

Estigmas que definen rumbos de indagación bajo pensamientos heredados, cargados de simbolismos que permiten identificar lo que la cultura es y debe ser. Sustratos que sirven a los propósitos de la educación, desde los que emerge el sentido de la vida y los fundamentos que la explican. Faros que señalan el punto de llegada para un pensamiento que divaga sobre el porqué de las cosas, sin dar margen al disenso o la confrontación; sitios de comodidad donde todo está dicho y resuelto, soportado por las lógicas de la razón, quienes imponen imperativos categóricos al saber. Eso y más representa el predominio de las disciplinas.

Si como afirman muchos especialistas, la era de la información es también del conocimiento, donde aprender a aprender es la base de todo sistema de vida, entonces habrá que pensar que la vida no puede ser constreñida a solo seguirle la pista al conocimiento. La simple idea de adquirir habilidades, destrezas y capacidades en las escuelas, dentro de un campo de saber determinado (especialización), delimita un sentido básico de lo que es la educación; formar para la vida no puede reducirse a la adopción de paradigmas, ya que estos, en su sentido kuhniano, tienden a ser sustituidos por otros. Aquí radica el meollo del asunto: se necesitan nuevos modelos conceptuales que sirvan de base a la aparición de formas emergentes de intervenir en la realidad, génesis de todo cambio cultural.

23. Alicia Inés Villa, «Cultura y educación, ¿una relación obvia?», Revista Oficios Terrestres, n. ${ }^{\circ} 18$ (2006): 34 , acceso: 2 de agosto, 2019, http://sedici.unlp.edu.ar/bitstream/handle/10915/46063/Documento_completo. pdf? sequence $=1 \&$ isAllowed $=y$

24. Tünnermann, Modelos educativos..., 9. 
El paralogismo que señala la construcción del conocimiento como función sustantiva del binomio maestro-estudiante oculta dentro de los modelos vigentes el hecho de que se refiere únicamente a construir sobre una base común e inmutable de saberes; es decir, sobre teorías que definen rumbo e intención, validas desde un campo disciplinario que asegura la eficacia del método; una especie de ascetismo metodológico que desestima el fin por privilegiar el medio.

Al respecto se debe considerar que el desarrollo de habilidades cognitivas y metacognitivas, logradas mediante andamiajes entre el conocimiento previo y el que está por adquirirse, necesita, para ser significativo, la gestión y negociación de saberes, lo que demanda integrar comunidades de diálogo, para trascender a partir de ahí a comunidades de aprendizaje y práctica. Aquí yacen los fundamentos para diseñar un modelo educativo que se nutra de la cultura de sus protagonistas.

\section{La educación como realización cultural}

Todo modelo educativo, para ser congruente y coherente con sus propósitos, debe dar respuesta a ciertas interrogantes: ¿Por qué educar? ¿Bajo qué contextos? ¿Qué intenciones se tienen? ¿Bajo qué premisas hacerlo? De aquí se desprende un diseño curricular cuya misión es alinearse con las respuestas, lo que entraña nuevos cuestionamientos: ¿Qué enseñar y cómo enseñarlo? ¿Qué aprender y cómo aprenderlo? ¿Dónde se puede enseñar mejor? ¿Qué contenidos deben incluirse? ¿Bajo qué estrategias se debe enseñar? ¿Cómo evaluar lo aprendido? Cauces que orientan la planeación educativa al condicionar una forma de enseñar y aprender; acotamientos metodológicos que además definen el pensamiento crítico y creativo de maestros, estudiantes y autoridades académicas, quienes generalmente conciben el currículo como prescriptivo y no como guía para la intervención.

Con ello se sustenta la justificación de un programa académico, un plan de estudios, una política educativa que los concibe y un plan general de participación de los colegiados académicos; pero decir qué hacer, no garantiza su concreción en la práctica. Con ello la didáctica es soslayada, en aras de una formación docente que no forma parte de la mejora continua de la mayoría de las instituciones de nivel superior, donde los cursos y talleres impartidos aisladamente, suele ser el denominador común.

En medio de tantas certidumbres institucionalizadas, expuestas como innovadoras, no es posible percibir con claridad la incorporación de la cultura dentro de los modelos educativos, ya que la atención se centra en la enseñanza y el aprendizaje disciplinar, que en el discurso oficial se visten de transversalidad e interdisciplina, ocultando tras su velo el dogmatismo y la autoridad cognitiva. Ya $\operatorname{Daros}^{25}$ lo indicaba al puntualizar que:

... los pueblos han sobrevivido en la medida en que aprendieron, esto es, en la medida en que experimentaron, reflexionaron y aprovecharon la experiencia reflexiva y vital para solucionar sus problemas y no cometer nuevamente los mismos errores. Porque con esas experiencias se

25. William Roberto Daros, Educación y cultura crítica (Rosario: Editorial CIENCIA, 1986), 5, edición en PDF, acceso: 2 de agosto, 2019, http://www.ucel.edu.ar/upload/libros/DAROS_Educacion_y_cultura_critica.pdf 
habían educado: no sólo habían mejorado sus inteligencias sino también sus voluntades, su praxis, su sentido de valores tales como la justicia, el amor, la convivencia pluralista, considerados frutos de un esfuerzo que era necesario convalidar constantemente.

Esto sintetiza la esencia de lo que se espera de un modelo educativo centrado en la cultura, al posibilitar una didáctica pluralista, democrática y participativa, articulada desde la comunicación y el aprendizaje comunitario y colaborativo, definido desde la práctica y asumida como escenario de formación. El propio Daros ${ }^{26}$ brinda el objetivo de esta propuesta, al indicar que «se trata de asegurar la libertad de pensamiento y acción en los que aprenden, de salvaguardar la pluralidad de criterios lo que hace críticos a los juicios y democrática a la vida». Para ello, habrá que examinar hasta dónde los estudiantes a su egreso exhiben un sentido crítico en sus disertaciones y argumentos, al valorar el nivel de discernimiento que poseen sobre su entorno, particularmente en la forma imaginativa y creativa con la que conciben la realidad mediata e inmediata. Verificar si los juicios que emplean se muestran plurales en sus fines y sus medios, aportará un perfil claro sobre el nivel de autonomía que muestran sus pensamientos y razonamientos al momento de indagar sobre los fenómenos de interés. Lo relevante estriba en saber qué tanta responsabilidad social proyectan en sus criterios, así como la pertinencia de sus principios y valores con respecto a los problemas socioambientales que enfrenta la humanidad.

Como se aprecia la tarea no es fácil. Es común que las instituciones de educación superior (particularmente las tecnológicas) no se interesen por saber si los egresados de un programa académico cumplen con el perfil de egreso propuesto, menos lo harán por verificar su formación cultural, sus habilidades sociales, sus principios éticos o su conciencia social, soslayándose que:

La educación que suprime el juicio crítico, que no despierta un sano sentido crítico, que no cultiva la creatividad, que se mueve sólo en términos de adaptación a la cultura vigente y observancia de un modelo rígidamente estático de sociedad, no es verdadera educación, sino amaestramiento, domesticación y abuso de dominio de unos sobre otros ${ }^{27}$.

Ante este escenario recurrente, es necesario incorporar la cultura como contexto y sustrato de la educación, no solo en el nivel superior, sino a lo largo del proceso formativo del estudiante, ya que como afirma Jiménez ${ }^{28}$ : «en todas las sociedades, la cultura es la matriz de la que se desprende la escuela, aunque en las estructuras de gobierno de muchos países, la relación entre educación y cultura es inversa, es decir, la cultura depende de la educación.» Supeditar la cultura a la educación, trae consigo el riesgo de sesgar los criterios de selección bajo estándares de grupo, lo que es una práctica común en América Latina. Decirle a otros qué de la cultura es necesario asimilar es de menos una manipulación, sobre todo cuando se hace de forma programada.

26. Ibíd., 5 .

27. Conferencia Episcopal Argentina, Educación y Proyecto de Vida (Buenos Aires: Equipo Episcopal de Educación Católica, 1984), s/p.

28. Lucina Jiménez, «La escuela ante la explosión de sus fronteras; los vínculos entre educación y cultura», Euroamericano, Campus de Cooperación Cultural (2005): 1, acceso: 2 de agosto, 2019, https://www.oei.es/ historico/euroamericano/ponencias_formacion_escuela.php\# 
En conceptos de Ariel-Olmos, se debe «educar en cultura» ${ }^{29}$, ya que: «toda acción educativa (formal, no formal, informal) es una construcción sociohistórica y, por tanto, en un sentido amplio, cultural». Es así como la cultura toma un sentido integral, al tratarse de formas de vida que se expresan en lo cotidiano, condiciones que hacen de los simbolismos y sus rituales elementos torales del propio saber. Ariel-Olmos ${ }^{30}$ precisa que:

... la educación es siempre emergente de una cultura entendida ésta como una forma integral de vida que es creada histórica y socialmente por una comunidad a partir de su particular manera de resolver física, emocional mentalmente las relaciones que mantiene con la naturaleza, consigo misma, con otras comunidades y con lo que ella considera sagrado para dar continuidad y plenitud de sentido a la totalidad de la existencia.

Pero es precisamente el distanciamiento que existe entre la educación y las formas de vida comunitarias, entendidas como entornos donde la cultura anida y se recrea a partir de las interacciones sociales y naturales, lo que ha devenido en una percepción sobrevalorada, pero ingenua, de lo que la educación puede lograr si se erige como base de la cultura. El ejemplo típico lo representa la Gran Ciencia (big science), la cual desde el modernismo se encuentra coligada a ciertos sectores de la sociedad ${ }^{31}$, no por ello a la cultura. Al respecto, Albornoz establece que «la política científica contemporánea, flanqueada por la política tecnológica y más recientemente por la política de innovación, encolumnada más o menos confusamente en las políticas del conocimiento, constituye un rasgo ineludible de las sociedades contemporáneas». Esta situación está exacerbada por la vertiente económica y la consecuente mercantilización del conocimiento, el cual se vuelve elitista y distante para las mayorías.

Bajo estándares que definen lo que debe ser el conocimiento y cómo debe ser interpretado, los Estados han incorporado en sus agendas públicas los lineamientos para su desarrollo, transformando el quehacer del investigador, al verse sujeto a esquemas ajenos a su idiosincrasia. Se presenta así una ciencia indefinida en su naturaleza y función ${ }^{32}$, lo que deja abierta la posibilidad al dogmatismo y la ignorancia ilustrada, que además se encuentra «teñida de valores y enmarañada en complejos problemas éticos» ${ }^{33}$. El resultado: una cultura adjetivada -cultura científica-, investida de saberes que se universalizan mediante quehaceres protocolares, donde el conocimiento es validado para todos.

29. Héctor Ariel Olmos, «Educar en cultura», Euroamericano, Campus de Cooperación Cultural (2005): 1, acceso: 2 de agosto, 2019, https://www.oei.es/historico/euroamericano/ponencias_formacion_educar.php

30. Ibíd., 1.

31. Debido al «protagonismo creciente de los gobiernos en el financiamiento y orientación de las actividades de investigación en las sociedades avanzadas». Mario Albornoz, «Los problemas de la ciencia y el poder», Revista CTS, 3, n. ${ }^{\circ} 8$ (2007): 47-65, acceso: 2 de agosto, 2019, http://www.revistacts.net/files/Volumen $\% 20$ $3 \% 20-\% 20$ N $\%$ FAmero $\% 208 /$ doss 02 .pdf

32. Principalmente porque la ciencia es interpretada desde la política, cuyos estatutos éticos/morales son opuestos a la misma; el resultado: una visión parcial y utilitarista de la ciencia y la investigación.

33. Albornoz, «Los problemas de..., 48 . 


\section{Conclusiones}

¿Qué brinda validez a un modelo educativo? ¿Acaso su congruencia con un contexto determinado y sus actores? ¿Quizá su eficacia para alcanzar los objetivos planteados? ¿O será su fidelidad al canon establecido? Para los puristas, la respuesta correcta se halla en la capacidad del modelo para recrear escenarios de actuación, inmutables en el tiempo y el espacio, aunque esto signifique rigidez conceptual y parálisis metodológica.

¿Se puede educar a partir de la cultura concebida como unidad integral? ¿Es posible dejar de adjetivar la cultura? Es decir, ya no más cultura científica o tecnológica -teoría de las dos culturas ${ }^{34}-$, incluso ecológica, política o económica. La segmentación del concepto es en sí misma una estrategia disciplinaria. Lo que subyace a estas divisiones de la cultura es un ejercicio de poder, que convierte a los códigos lingüísticos y las matrices semánticas que le acompañan en instrumentos de control, sostenidos por el statu quo de quienes ostenta la supremacía cultural.

Al ser la cultura un sistema de prácticas formalizadas por la interacción dialéctica de las personas inmersas en los grupos sociales, que esclarece el sistema de códigos a los que se ven sujetos voluntariamente, se afirma que la cultura incluye el componente de la percepción personal, las representaciones sociales y actitudes como reflejo de los valores compartidos. Ello es lo que hace de la ciencia, tecnología, ecología, política o los sistemas económicos, subculturas que llegan a cobrar autonomía y que compiten entre sí, como es el caso de la ciencia y la tecnología; campos para algunos imbricados y para otros incluyentes, ya que «la progresiva tecnificación de la ciencia y de cientificación de la tecnología, la comprensión actual de los procesos de innovación y la conformación de la sociedad del conocimiento implican una estrecha articulación, e incluso fusión ${ }^{35}$.

En todo caso, el verdadero desafío es pensar en una contracultura escolar que trascienda los tradicionales modelos educativos. En conceptos de Hererra-Zavaleta ${ }^{36}$, la contracultura debe ser vista como un paradigma que permite comprender el acontecer de las expresiones culturales alternativas a un sistema. De acuerdo con él, se incluye en ella diversas manifestaciones: «artísticas, científicas, sociales, filosóficas, económicas y políticas, contrarias o diferentes a la Cultura Oficial [...]; es una forma específica de ver la realidad, establece límites a lo hegemónico, formula interrogantes, introduce enigmas en el imaginario social».

Dimensiones necesarias cuando el propósito sea diseñar un modelo educativo alternativo a las propuestas científico/tecnológicas, que responda a los principios de la

34. Aplicable también para tecnología vs. humanismo, ciencias sociales vs. ciencias naturales. Aunque «lo que se puede apreciar hoy es que existen aperturas desde las ciencias naturales hacia las ciencias sociales y viceversa, o bien aperturas de las ciencias naturales hacia las humanidades recíprocamente». María Adelaida López-Alzate, «Fragmentación entre ciencia y humanismo en la universidad contemporánea», Hallazgos, 11, n. 22 (2014): 336, acceso: 2 de agosto, 2019, http://www.scielo.org.co/pdf/hall/v11n22/v11n22a18.pdf

35. Jesús Sebastián, «La cooperación universitaria para el fomento de la cultura científica», Euroamericano, Campus de Cooperación Cultural (2005): 1, acceso: 2 de agosto, 2019, https://www.oei.es/historico/euroamericano/ponencias_ciencia_cooperacionuniversitaria.php

36. José Luis Herrera-Zavaleta, «Filosofía y contracultura», Quaderns de filosofia i ciència, n. ${ }^{\circ} 39$ (2009): 73 , acceso: 2 de agosto, 2019, https://www.uv.es/sfpv/quadern_textos/v39p73-82.pdf 
autopoiesis ${ }^{37}$ de los sistemas sociales -de tercer orden-, donde los seres humanos deben constituirse en componentes autopoiéticos, sin descartar el componente comunicativo expuesto por Luhmann ${ }^{38}$, lo que permita ascender hacia los denominados sistemas de interacción ${ }^{39}$ social autopoiéticos, donde, a diferencia de Maturana, quien piensa en la cultura como un sistema autopoiético que existe en un espacio de conversaciones, se conciba al sistema ${ }^{40}$ como un espacio de gestión y negociación de saberes. Abordar el diseño de modelos educativos desde la denominada tercera generación de pensamiento sistémico responde, a decir de Martínez-Dávila y Bustillo-García ${ }^{41}$, «al triple desafío de interdependencia, auto-organización y libertad de elección, en el contexto de los sistemas socioculturales».

Sin dejar de reconocer lo complejo que resulta conciliar la cultura con lo educativo, esta puede ser una rica veta para pensar el desarrollo del talento humano como base de la sociedad.

\section{ABSTRACT}

\section{Cultural fundamentals for an emerging educational model in higher technological education}

The tendency to privilege social progress through education has conditioned the design of educational models centered on science and technology. From this perspective, the acquisition of skills for work is favored, avoiding the importance of culture as a generator of training programs. Based on this, an alternative proposal is presented for the design of educational models thought from the culture, whose purpose is the integral formation and the development of the human talent.

Key words: Human development, culture, humanism.

37. Caracterizada por la capacidad de crear y mantener la propia organización como sistema en los seres vivos. Sandra Liliana Daza-Cuartas, «Sujeto autopoiético y pedagogía creativa», Novum, Revista de Ciencias Sociales Aplicadas, n. ${ }^{\circ}$ 3, (2010): 95-102, acceso: 2 de agosto, 2019, https://revistas.unal.edu.co/ index.php/novum/article/view/67131

38. Niklas Luhmann, Sistemas sociales (México: Editorial Iberoamericana, 1991).

39. Interacción social como fenómeno básico.

40. Se piensa en problematizar acerca del lugar que ocupa la cultura en la diferenciación de la sociedad, indagando acerca de los límites que esta tiene dentro de la misma, así como de aquello que la distingue. Hugo Cadenas, "Cultura y diferenciación de la sociedad: La cultura en la sociedad moderna», Polis, Revista Latinoamericana, 13, n. ${ }^{\circ} 39$ (2014): 250, acceso: 2 de agosto, 2019, https://scielo.conicyt.cl/pdf/ polis/v13n39/art12.pdf

41. Juan Pablo Martínez-Dávila y Lissette Bustillo-García, «La autopoiesis social del desarrollo rural sustentable», Interciencia, 35, n. ${ }^{\circ}$ 3, (2010): 224, acceso: 2 de agosto, 2019, http://www.redalyc.org/ pdf/339/33913157013.pdf 


\section{RÉSUMÉ}

\section{Fondements culturels pour un modèle émergent dans l'enseignement supérieur technologique}

La tendance à privilégier le progrès social à partir de l'enseignement a conditionné la conception des modèles éducatifs centrés sur la science et la technologie. Dans cette perspective, l'acquisition des habilités pour le travail se favorise tandis que l'importance de la culture comme génératrice des programmes formatifs est contournée. Sur cette base, cet article présent une proposition alternative pour la création des modèles éducatifs conçus dès la culture dont le but est la formation intégrale et le développement du talent humain.

Mots clés: Développement humain, culture, humanisme.

\section{Referencias bibliográficas}

Albornoz, Mario. «Los problemas de la ciencia y el poder». Revista CTS 3, n. ${ }^{\circ} 8$ (2007): 47-65. Acceso: 6 de agosto de 2019. http://www.revistacts.net/files/Volumen $\% 203 \% 20-\% 20$ N\%FAmero\%208/doss02.pdf

Altieri-Megale, Angelo. «¿Qué es la cultura?». La Lámpara de Diógenes 2, n. ${ }^{\circ} 4$ (2001): 15-20. Acceso: 6 de agosto de 2019. https://www.redalyc.org/pdf/844/84420403.pdf

Apodaca-Orozco, Ginne Ussi Guadalupe, Lourdes Patricia Ortega Pipper, Luz Ester Verdugo Blanco y Laura Elena Reyes Barribas. «Modelos educativos: un reto para la educación en salud». Ra Ximhai 13, n. ${ }^{\circ} 2$ (2017): 77-86. Acceso: 6 de agosto de 2019.https://www.redalyc.org/pdf/461/46154510006.pdf

Ariel-Olmos, Héctor. «Educar en cultura». Euroamericano, Campus de Cooperación Cultural (2005): 1. Acceso: 6 de agosto de 2019. https://www.oei.es/historico/euroamericano/ponencias_formacion_educar.php

Bayardo, Rubens. «La economía cultural, las políticas culturales y el financiamiento público de la cultura». Turismo y Patrimonio, n. $^{\circ} 4$ (2018): 57-68. Acceso: 6 de agosto de 2019. http://ojs.revistaturismoypatrimonio. com/index.php/typ/article/view/143

Bayardo, Rubens. «Sobre el financiamiento público de la cultura. Políticas culturales y economía cultural». NAyA (2002): 3. Acceso: 6 de agosto de 2019. http://www.equiponaya.com.ar/congreso2002/ponencias/ rubens_bayardo.htm

Cadenas, Hugo. "Cultura y diferenciación de la sociedad: La cultura en la sociedad moderna». Polis, Revista Latinoamericana 13, n. ${ }^{\circ} 39$ (2014): 249-274. Acceso: 6 de agosto de 2019. https://scielo.conicyt.cl/pdf/ polis/v13n39/art12.pdf

Carbó-Ribugent, Gemma (coordinadora). La cultura, estrategia de cooperación al desarrollo. Girona: Documenta Universitaria, 2008

Conferencia Episcopal Argentina. Educación y Proyecto de Vida. Buenos Aires: Equipo Episcopal de Educación Católica, 1984

Daros, William Roberto. Educación y cultura crítica. Rosario, Argentina: Editorial CIENCIA, 1986. Acceso: 6 de agosto de 2019. http://www.ucel.edu.ar/upload/libros/DAROS_Educacion_y_cultura_critica.pdf

Daza-Cuartas, Sandra Liliana. «Sujeto autopoiético y pedagogía creativa». Novum, Revista de Ciencias Sociales Aplicadas, n. 3 (2010): 95-102. Acceso: 6 de agosto de 2019. https://revistas.unal.edu.co/index.php/ novum/article/view/67131

Díaz-Caballero, José Ricardo. «Humanismo y tecnología». Revista Cubana de Ingeniería 1, n. ${ }^{\circ} 2$ (2010): 71-74. Acceso: 6 de agosto de 2019. http://rci.cujae.edu.cu/index.php/rci/article/view/22/23 
Guerrero-Agripino, Luis Felipe. Modelo Educativo de la Universidad de Guanajuato. Guanajuato: Universidad de Guanajuato, 2011. Acceso: 6 de agosto de 2019. http://www.ugto.mx/images/pdf/modelo-educativo-ysus-modelos-academicos-universidad-de-guanajuato.pdf

Herrera, Luis. «La educación y la cultura: una lectura y propuesta desde la filosofía de la praxis». Sophia, Colección de Filosofía de la educación, n. ${ }^{\circ} 1$ (enero-junio 2006): 186-231. Acceso: 6 de agosto de 2019. http:// www.redalyc.org/pdf/4418/441846111004.pdf

Herrera-Zavaleta, José Luis. «Filosofía y contracultura». Quaderns de filosofia i ciència, n. ${ }^{\circ} 39$ (2009): 73-82. Acceso: 6 de agosto de 2019. https://www.uv.es/sfpv/quadern_textos/v39p73-82.pdf

Hualde, Alfredo. «La educación y la economía del conocimiento: una articulación problemática». Revista de la Educación Superior 34, n. ${ }^{\circ} 136$ (2005): 107-127. Acceso: 6 de agosto de 2019. http://publicaciones.anuies. $\mathrm{mx} /$ acervo/revsup/pdf/RES_136.pdf

Jiménez, Lucina. «La escuela ante la explosión de sus fronteras; los vínculos entre educación y cultura». Euroamericano, Campus de Cooperación Cultural (2005): 1. Acceso: 6 de agosto de 2019. https://www.oei.es/ historico/euroamericano/ponencias_formacion_escuela.php\#

López-Alzate, María Adelaida. «Fragmentación entre ciencia y humanismo en la universidad contemporánea». Hallazgos 11, n. 22 (2014): 329-357. Acceso: 6 de agosto de 2019.http://www.scielo.org.co/pdf/hall/ v11n22/v11n22a18.pdf

Luhmann, Niklas. Sistemas sociales. México: Editorial Iberoamericana, 1991.

Maraña, Maider. Cultura y desarrollo. Evolución y perspectivas. España: UNESCO/Etxea, 2010. Acceso: 6 de agosto de 2019. http://www.unescoetxea.org/dokumentuak/Cultura_desarrollo.pdf

Martínez-Dávila, Juan Pablo y Lissette Bustillo García. «La autopoiesis social del desarrollo rural sustentable». Interciencia 35, n. 3 (2010): 223-229. Acceso: 6 de agosto de 2019.http://www.redalyc.org/ pdf/339/33913157013.pdf

Massimino-Amoresano, Laura. «Tecnología y educación: El humanista tecnólogo. Deconstruyendo la frontera entre las dos culturas». ILCEA, n. ${ }^{\circ} 18$ (2013). Acceso: 6 de agosto de 2019. https://journals.openedition. org/ilcea/2096

Maturana, Humberto y Francisco Varela. De máquinas y seres vivos. Santiago: Editorial Universitaria, 1995.

Merçon, Juliana, Andrés Camou Guerrero, Cristina Núñez Madrazo y Miguel Ángel Escalona Aguilar. «¿Diálogo de saberes? La investigación acción participativa va más allá de lo que sabemos». Desicio, n. ${ }^{\circ} 38$ (2014): 29-33. Acceso: 6 de agosto de 2019. https://cdn.crefal.org/CREFAL/revistas-decisio/decisio38_saber6.pdf

Minguet-Melián Jesús María y Tim Read. Informática Fundamental. Madrid: Editorial Universitaria Ramón Areces, 2008.

Morin, Edgar y Carlos Jesús Delgado Díaz. Reinventar la educación. Abrir caminos a la metamorfosis de la humanidad. México: UH, 2017.

Murueta Marco Eduardo, Menchaca-García Felipe Rolando, Garcés-Chávez Juan Manuel, Partida Ernesto, Sillas Teresa, Evaristo Hernández Fernando, Badillo-Hernández Pedro, Zárate Moreno Laura, Alcaraz Fernando, Gallástegui Javier. Hacia un nuevo modelo educativo integral. En: «Nuevos modelos educativos» (22-31). México: Manual Moderno, 2015. Acceso: 6 de agosto de 2019. https://www.transformacioneducativa.com/attachments/article/153/Libro $\% 2008 \% 20-\% 20$ Nuevos $\% 20$ modelos $\% 20$ educativos.pdf

Ocampo-Almazán, Alejandro. «Humanismo y tecnología: algunas ideas para salir de la exclusión». Razón y Palabra. Primera Revista Electrónica en Iberoamérica Especializada en Comunicación, n. ${ }^{\circ} 89$ (2015): 1-9. Acceso: 6 de agosto de 2019. http://www.razonypalabra.org.mx/N/N89/V89/25_Ocampo_V89.pdf 
Piedra-Calderón, Juan Carlos, Rubén González Crespo y José Javier Rainer. «Sociedades tecnológicas». Sociedad y Utopía. Revista de Ciencias Sociales, n. 44 (2014): 18-33. Acceso: 6 de agosto de 2019. http://www. sociedadyutopia.es/images/revistas/44/E01.pdf

Sebastián, Jesús. «La cooperación universitaria para el fomento de la cultura científica». Euroamericano, Campus de Cooperación Cultural (2005): 1. Acceso: 6 de agosto de 2019. https://www.oei.es/historico/euroamericano/ponencias_ciencia_cooperacionuniversitaria.php

Tünnermann, Bernheim Carlos. Modelos educativos y académicos. Nicaragua: Editorial HISPAMER, 2008.

Universidad de Deusto. Reflexiones y perspectivas de la educación superior en América Latina. Bilbao, España: RGM, S.A., 2007. Acceso: 6 de agosto de 2019. http://tuningacademy.org/wpcontent/uploads/2014/02/ TuningLAIII_Final-Report_SP.pdf

Villa, Alicia Inés. «Cultura y educación, ¿una relación obvia?». Revista Oficios Terrestres, n. ${ }^{\circ} 18$ (2006): 34-43. Acceso: 6 de agosto de 2019. http://sedici.unlp.edu.ar/bitstream/handle/10915/46063/Documento_completo.pdf?sequence $=1 \&$ is Allowed $=y$ 